\title{
A STUDY OF PAIN PERCEPTION DURING THE DIFFERENT PHASES OF MENSTRUAL CYCLE
}

Rolinda Rajkumari, Joshna Thiyam, Susie Keithellakpam, Ng. Javan, S. Thoibahenba

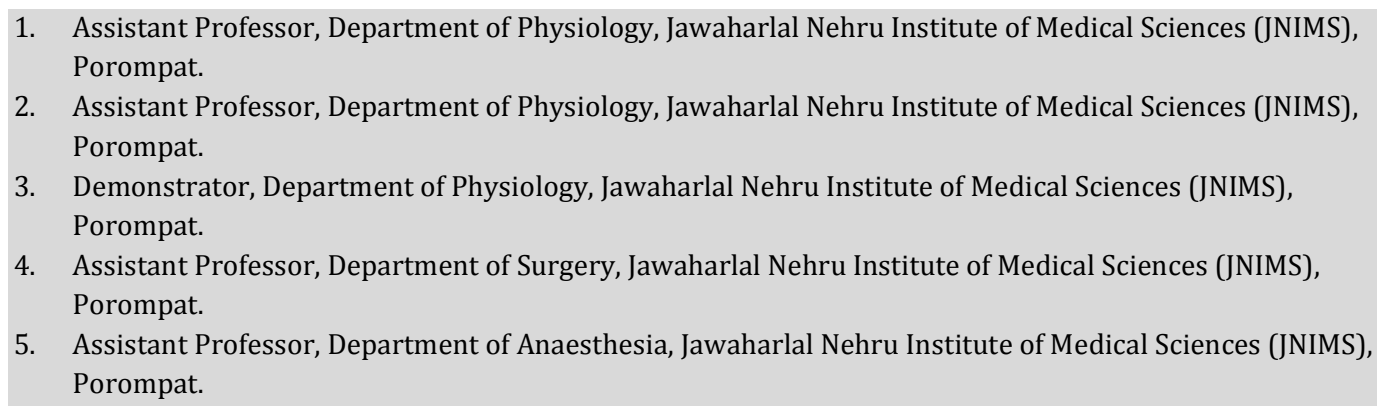

\section{CORRESPONDING AUTHOR}

Dr. Rolinda Rajkumari,

Assistant Professor, Department of Physiology,

Jawaharlal Nehru Institute of Medical Sciences, Porompat,

Imphal-East, Manipur

E-mail: rolinda_rk65@rediffmail.com

Ph: 00919612002129.

\begin{abstract}
Animal and human research has shown that pain perception changes across the menstrual cycle. This has sometimes been attributed to hormonal variation. The aim of the present study was to examine how perception of pain, induced by cold pressor test in dominant hand, is related to phases of the menstrual cycle. Twenty-five female students were included in the study. The cycle phase during which each woman began her participation was randomized. Pain was induced using the cold pressor test. Pain threshold was determined as the duration of time between the subject's first reported pain and exposure to the painful stimulus. Pain tolerance was determined as the duration of the time until the subject withdrew her hand from the cold water as the pain was too intensive. The results showed that both the mean pain threshold and mean pain tolerance were significantly higher in follicular phase compared with luteal phase. We can conclude from our study that pain perception varies across the menstrual cycle as shown by higher pain threshold and tolerance during follicular phase of menstrual cycle.
\end{abstract}

KEY WORDS: menstrual cycle, pain threshold, pain tolerance.

INTRODUCTION: In general, the human menstrual cycle is divided into three phases: the follicular phase, ovulatory phase and luteal phase. This cycle is regulated by variation in gonadal hormones such as estrogen and progesterone.

Evidence from an epidemiological study have found that there is an increased risk of temporomandibular disorder pain in young women using oral contraceptives and in postmenopausal women on hormone replacement therapies (1). Additionally, a large proportion of women report increase in pain- related symptoms at certain phases of menstrual cycle such as premenstrual migraines (2). Reproductive life events and sex hormone alterations have also been found related to fibromyalgia, rheumatoid arthritis, and irritable-bowel syndrome (3-5). Cyclical fluctuation of gonadal steroids may provide a partial explanation for 
the increased pain perception that has been reported in women, a possibility also suggested by compelling clinical evidence that a very common episodic pain syndrome, migraine, often recurs in women with a clear-cut menstrual periodicity (6). Similarly, several animal studies suggests that gonadal hormones could influence response to painful stimuli among female, for instance, response to noxious stimuli are influenced by estrous cycle phase in rats and stress-induced analgesia varies across the estrous cycle in rats $(7,8)$.

However, the results of numerous pain studies conducted in women, examining possible variations related to the menstrual phase, in response to experimentally induced noxious stimulation showed no conclusive findings (9-11).The present study was conducted to examine how perception of pain, induced by cold pressor test in dominant hand, is related to the phases of the menstrual cycle.

MATERIAL \&METHODS: This study was conducted among the first year MBBS students (201011 batch) of the Jawaharlal Nehru Institute of Medical Sciences, Imphal. Twenty Five female students volunteered for the study all of whom fulfilled the inclusion criteria; age between 1822 yrs, regular menstrual cycle (28 44 days) and Body Mass Index (BMI) $<28 \mathrm{Kg} / \mathrm{m} 2$. The exclusion criteria were gynecological diseases, endocrine disorders, hormonal therapy, drug abuse, alcohol intake, acute and chronic pain as well as dermatosis at the site of the pain stimulation. Each student underwent test in two different phases of the menstrual cycle (days 24 and days 20-24). The students were told not to use pain medication 24 hours before the test. The cycle phase during which each student began her participation was randomized.

COLD PRESSOR TEST: It was used as a stimulus source. The dominant hand was immersed up to the wrist in ice chilled water $(40 \mathrm{C} \pm 10)$. The water bucket (2.8 lits) was shaken manually by the experimenter every 30 second from warming up around the skin. The temperature in the bucket was measured by mercury thermometer (INCO immersion thermometer) and was made not to exceed $6^{0} \mathrm{C}$. The participants were instructed to hold their hands as long as they could bear the pain and to inform when pain is first felt. Pain threshold was determined as the duration of time between the subject's first reported pain and exposure to the painful stimulus. Pain tolerance was determined as the duration of the time until the subject withdrew her hand from the cold water as the pain was too intensive.

Informed and written consent were taken from the students after explaining the details of the test and were told that anyone could walk out from this study at any time without giving reason. The research was carried out after taking the clearance from the ethical committee of the Institution. It was done using SPSS 13. All the values were expressed as mean \pm SD. Comparisons were done using students "un-paired t test". Statistical significance was considered to be present when the two-tailed probability was less than 0.05

RESULTS: The table 1 shows comparison of pain threshold and tolerance between the follicular phase and luteal phase of the menstrual cycle. The mean pain threshold was significantly higher in follicular phase compared to luteal phase $(\mathrm{p}<0.05)$. The mean pain tolerance is found to be higher in follicular phase as compared to the luteal phase $(\mathrm{p}<0.01)$.

DISCUSSION: The present study have shown higher pain threshold in follicular phase of the menstrual cycle. Stening et al (9) demonstrated that the follicular phase has longer activation 
time as compared to luteal phase during the hand cold pressor. Teepker et al (12) have also revealed from their study on thirty-two healthy and pain free women having regular menstrual cycle that the pain threshold increased during the menstrual cycle from day 1 to day 14 for cold. In contrast to our study, Hellstrom and Lundberg (10) revealed a significantly higher pain threshold during the second half of the menstrual cycle. Furthermore, Kowalczk et al (11) found no significant changes in cold pain threshold as a function of menstrual cycle phase.

Our study also showed higher pain tolerance during the follicular phase of the menstrual cycle. Hapidou and de Catanzaro (13) reported higher pain tolerance during the follicular period which is similar with our study. However, Stenting et al (9) have reported no significant changes in the pain tolerance time of the cold pressor test during the menstrual cycle in sixteen students. This could be due to the fact that they have kept the cut-off limit for tolerance time as 300 seconds in which many participants had reached the cut-off limit.

It is difficult to explain from the present study that pain perception alters with the phases of menstrual cycle. However, previous study demonstrates less pain sensitivity during phases of the menstrual cycle associated with high estrogen (14). Many estrogen receptor expressing neurons are opioidergic (15) and show increased opioid transcription upon 17 $\beta$ estradiol administration (16). Previous study also reveals ovarian sex steroid antinociception as opioid mediated and results from the activation of spinal cord $\kappa$ and $\delta$ opiate receptors (17).

However, another study on animals show estradiol does not consistently modulate sensitivity to analgesic effects of opioids in the adult organism (18).

Stening et al (9) demonstrated a significant correlation between the S-progesterone level and reduced activation time during the luteal phase suggesting progesterone to be pronociceptive. Animal studies indicates that the induction of luteinizing hormone (LH) surge leads to a diminished analgesic response to morphine resulting from desensitization of brain opiate receptors (19). Thus, one can speculate that hormonally induced (ovulation) opiate receptor desensitization could enhance luteal phase pain sensitivity among women.

We can conclude from our study that pain perception varies across the menstrual cycle as shown by higher pain threshold and tolerance during follicular phase of menstrual cycle.

LIMITATION OF THE STUDY: In the present study the sample size was relatively small. Another limitation is the non-assessment of the hormonal level in our study.

ACKNOWLEDGEMENT: We would like to thank R. K. Pritam and L. Biseshwor for their technical assistance.

\section{REFERENCES:}

1. LeResche L, Saunder K, Von Korff MR, Barlow W, Dworkin SF. Use of exogenous hormones and risk for temporomandibular disorder pain. Pain 1997; 69: 153-6.

2. Silberstain SD, Merriam GR. Sex hormones and headache. J Pain Symptom Manage.1993; 8:98-114.

3. Ostensen M, Rugelsjoen A, Wigers SH. The effect of reproductive events and alterations of sex hormones levels on the symptoms of fibromyalgia. Scand J Rheumatol 1997; 26: 355-60

4. Da Silva JA, Hall GM. The effects of gender and sex hormones on outcome in rheumatoid arthritis. Baillieres Clin Rheumatol 1992; 6: 196-219.

5. Heitkemper MM, Jarrett M, Caudell KA, Bond E. Women with gastrointestinal symptoms: implications for nursing research and practice. Gastroenterol Nurs 1993; 15: 226-32. 
6. Facchinetti F, Martignoni E, Fioroni L, Sances G, Genazzani AR. Opioid control of the hypothalamus-pituitary-adrenal axis cyclically fails in menstrual migraine. Cephalalgia 1990; 10: 51-6

7. Frye CA, Cuevas Ca, Kanarek RB. Diet and estrous cycle influence pain sensitivity in rats. Pharmacol Biochem Behav 1993; 45: 255-260.

8. Ryan SM, Maier SF. The estrous cycle and estrogen modulate stress induced analgesia. Behav Neurosci 1988; 102:371-380.

9. Stening K, Eriksson O, Wahren L, Berg G, Hammar M, Blomqvist A. Pain sensations to the cold pressor test in normally menstruating women: comparison with men and relation to menstrual phase and serum sex steroid levels. Am J Physiol Regul Integr Comp Physiol. 2007; 293(4): R1711-6.

10. Hellström B, Lundberg U. Pain perception to the cold pressor test during the menstrual cycle in relation to estrogen levels and a comparison with men. Integr Physiol Behav Sci. 2000; 35(2): 132-41.

11. Kowalczyk WJ, Evans SM, Bisaga AM, Sullivan MA, Comer SD. Sex differences and hormonal influences on response to cold pressor pain in humans. J Pain. $2006 ; 7(3)$ : 151-60.

12. Teepker M, Peters M, Vedder H, Schepelmenn K, Lautenbacher S. Menstrual variation in experimental pain: correlation with gonadal hormones. Neuropsychobiology 2010; 61: 131-140.

13. Hapidou EG, De Catanzaro D. Sensitivity to cold pressor pain in dysmenorrheic and nondysmenorrheic women as a function of menstrual cycle phase. Pain 1988; 34: 277-283.

14. Hellstrom B, Anderberg UM. Pain perception across the menstrual cycle phases in phases in women with chronic pain. Percept Mot Skills 2003; 96(1): 201-211.

15. Amandusson A, Hermanson O, Blomqvist A. Colocalization of oestrogen receptor immunoreactivity and preproenkephalin mRNA expression to neurons in the superficial laminae of the spinal and medullary dorsal horn of rats. Eur J Neurosci 1996; 8: 24402445.

16. Amandusson A, Hallbeck M, Hallbeck AL, Hermanson O, Blomqvist A. Estrogen-induced alterations of spinal cord enkephalin gene expression. Pain 1999; 83: 243-248.

17. Dawson-Basoa M, Gintzler AR. Gestational and ovarian sex steroid antinociception: synergy between spinal kappa and delta opioid systems. Brain Res 1998; 794: 61-67.

18. Tassorelli C, Sandrini G, Cecchini A P, Nappi R E, Sances G, Martignoni E. Changes in Nociceptive Flexion Reflex Threshold Across the Menstrual Cycle in Healthy Women. Psychosomatic Medicine 2002; 64:621-626.

19. Berglund LA, Derendorf H, Simpkins JW. Desensitization of brain opiate receptor mechanisms by gonadal steroid treatments that stimulate luteinizing hormone secretion. Endocrinology 1988; 122: 2718-26.

Table 1: Comparison of pain threshold and tolerance between follicular phase and luteal phase.

\begin{tabular}{|l|l|l|}
\hline Pain & Follicular phase (mean \pm SD) & $\begin{array}{l}\text { Luteal phase } \\
(\mathbf{m e a n} \pm \text { SD) }\end{array}$ \\
\hline Threshold (seconds) & $24.52 \pm 12.89^{*}$ & $14.80 \pm 7.24$ \\
\hline Tolerance (seconds) & $25.56 \pm 27.97^{* *}$ & $17.68 \pm 7.24$ \\
\hline
\end{tabular}

$\mathrm{P}^{*}<0.05 ; \mathrm{p}^{* *}<0.01$ 